\title{
Endoscopic papillary balloon dilatation may preserve sphincter of Oddi function after common bile duct stone management: evaluation from the viewpoint of endoscopic manometry
}

H Sato, T Kodama, J Takaaki, Y Tatsumi, T Maeda, S Fujita, Y Fukui, H Ogasawara, S Mitsufuji

\begin{abstract}
Background-Endoscopic papillary balloon dilatation (EPBD) has been reported as a safe and effective alternative to endoscopic sphincterotomy in the management of common bile duct (CBD) stones; its effect on papillary function has yet to be elucidated.

Aim-To investigate sphincter of Oddi (SO) motility before and after EPBD to determine its effect on SO function.

Patients and methods-The papillary function of 10 patients with CBD stones was studied using endoscopic manometry before and one week after EPBD. The manometric studies were repeated one month after EPBD in seven patients.

Results-One week after EPBD, CBD pressure, SO peak pressure, SO basal pressure, and SO frequency decreased significantly. One month after EPBD, however, all parameters increased although the increases in SO basal pressure and CBD pressure were not significant. There was no significant difference in values of any parameter before and one month after EPBD. No serious complications occurred.

Conclusion-These data suggest at least partial recovery of papillary function one month after the procedure. EPBD seems to preserve papillary function in treatment of CBD stones; a longer term follow up study with SO manometry should be performed to clarify the effect of EPBD on SO function.

(Gut 1997; 41: 541-544)
\end{abstract}

Keywords: endoscopic papillary balloon dilatation; sphincter of Oddi

Endoscopic sphincterotomy (EST) is widely accepted as an effective procedure for removing common bile duct (CBD) stones. There is however concern that EST may alter the structure and motor function of the sphincter of Oddi (SO) for a long period of time in young patients having laparoscopic cholecystectomy. ${ }^{12}$ Endoscopic papillary balloon dilatation (EPBD) has been proposed as a less invasive alternative for CBD stone management. ${ }^{1-4}$ Based on animal studies, EPBD is expected to preserve papillary smooth muscle integrity in humans. ${ }^{5}$ In this study, we investigated SO motility before and after EPBD to determine its effect on SO function up to one month after the procedure.

\section{Patients and Methods}

Ten patients (five women and five men; mean age 70 years, range 52-92 years) undergoing EPBD for removal of CBD stones were studied. No patient had had any upper abdominal operation before EPBD. Although five patients had simultaneous gall bladder stones, all refused cholecystectomy mainly because of their age. Before EPBD, patients underwent SO manometry studies and endoscopic retrograde cholangiography (ERC) at the same session. The same sequence was used for the study one week after EPBD in all patients. One month later, only the manometric study was repeated, with measurement of CBD diameter by ultrasound image, in seven patients.

Manometry was performed before ERC, and pharyngeal topical anaesthesia (lidocaine spray) was given prior to SO manometry. ${ }^{6-8} \mathrm{~A}$ 4-French microtransducer catheter (Gaeltec Ltd, Dunvegam, Isle of Skye, Scotland, UK) was inserted into the CBD through a biopsy channel of the duodenofibrescope (Olympus JF200 or TJF20, Olympus, Tokyo, Japan), and fluoroscopy was used to confirm that the tip of the microtransducer was deeply inserted into the bile duct for a few seconds. ${ }^{67}$ CBD pressure and SO pressure were determined through the waveforms obtained by the stationary pull through method. SO pressure and CBD pressure were calibrated with the basal duodenal pressure as zero reference. Parameters measured were CBD pressure $(\mathrm{mm} \mathrm{Hg})$, $\mathrm{SO}$ basal pressure $(\mathrm{mm} \mathrm{Hg}), \mathrm{SO}$ peak pressure $(\mathrm{mm} \mathrm{Hg})$, and SO frequency (per minute).

At the end of manometry, $20 \mathrm{mg}$ of scopolamine butylbromide was given intravenously and $25 \mathrm{mg}$ of hydroxyzine or $5-10 \mathrm{mg}$ of diazepam intramuscularly at the start of ERC. After diagnostic ERC, a guidewire was placed in the CBD. A balloon tipped biliary catheter (Olbert catheter system, Boston Scientific Corporation, USA) was passed over the guidewire and was inflated to a diameter of $10 \mathrm{~mm}$ for one minute, repeated three times across the papilla. After dilatation, the CBD stones were extracted by dormia basket, retrieval balloon, or mechanical lithotripsy. 
Complications of EPBD were evaluated according to the consensus document published by Cotton et al in $1991 .^{9}$ The bile duct size was measured by ERC or abdominal ultrasound sonography.

The nature of the study was explained to each patient prior to the procedure. All procedures were done with the patients' consent. The study was performed in accordance with the principles stated in the Declaration of Helsinki, and was approved by the Ethical Committee of the Kyoto Prefectural University of Medicine.

For each parameter, mean and standard error were calculated. Data were analysed with the paired $t$ test (two tailed) for two groups and analysis of variance followed by the Duncan multiple range test for more than two groups. A value of $\mathrm{p}<0.05$ was considered significant.

\section{Results}

Table 1 shows SO manometry in the 10 patients before and one week after EPBD. One week after EPBD, all parameters decreased significantly with respect to values before EPBD (compared using the paired $t$ test). Figures 1-4 show SO parameters in seven patients before, one week after, and one month after EPBD. One week after EPBD, all SO parameters also showed a significant decrease with respect to the pre-EPBD values: CBD pressure from $7.3(1.0)$ to $3.9(0.4) \mathrm{mm} \mathrm{Hg}(\mathrm{p}<0.01)$; SO basal pressure from 13.6 (1.3) to $6.3(1.0)$ $\mathrm{mm} \mathrm{Hg}(\mathrm{p}<0.01)$; SO peak pressure from 109.8 (5.5) to $57.1(7.0) \mathrm{mm} \mathrm{Hg}(\mathrm{p}<0.01)$; and SO frequency from $6.9(0.5)$ to $3.4(0.5)$ per minute $(p<0.01)$. One month after EPBD, the following parameters had significantly increased compared with values one week after EPBD: SO peak pressure to $88.0(9.8) \mathrm{mm} \mathrm{Hg}$ $(\mathrm{p}<0.05)$; and SO frequency to $5.6(0.6)$ per minute $(p<0.01)$. SO basal pressure increased non-significantly to 9.3 (2.1) $\mathrm{mm} \mathrm{Hg}$ and CBD pressure to $5.9(0.7) \mathrm{mm} \mathrm{Hg}$. There was no significant difference in values of any parameter before and one month after EPBD.

The mean diameter of CBD stones was $9.3 \mathrm{~mm}$ (range $3-18 \mathrm{~mm}$ ) and number was 2.1 (range 1-7). All were successfully removed with EPBD. No significant changes in bile ducts size were found before $(13.2(1.0) \mathrm{mm})$, one week after $(12.8(1.0) \mathrm{mm})$, and one month after EPBD (12.6 (1.2) mm). None of the patients had severe complications such as bleeding, perforation, pancreatitis, infection, or

TABLE 1 Sphincter of Oddi manometry in 10 patients before and one week after endoscopic papillary balloon dilatation (EPBD)

\begin{tabular}{lrl}
\hline & Before EPBD & $\begin{array}{l}\text { One week after } \\
\text { EPBD }\end{array}$ \\
\hline $\begin{array}{l}\text { CBD pressure (mm Hg) } \\
\text { SO basal pressure (mm }\end{array}$ & $7.1(0.8)$ & $4.1(0.3)^{\star \star}$ \\
$\quad \mathrm{Hg})$ & $11.7(1.4)$ & $6.5(0.8)^{\star}$ \\
$\begin{array}{l}\text { SO peak pressure (mm } \\
\quad \text { Hg) }\end{array}$ & $109.9(4.8)$ & $55.8(5.0)^{\star \star}$ \\
$\begin{array}{l}\text { SO frequency (per } \\
\text { minute) }\end{array}$ & $6.8(0.4)$ & $3.1(0.3)^{\star \star}$ \\
\hline
\end{tabular}

Results are expressed as mean (SEM)

CBD, common bile duct; SO, sphincter of Oddi.

${ }^{\star} \mathrm{p}<0.05,{ }^{\star \star} \mathrm{p}<0.01$ compared with values before EPBD.

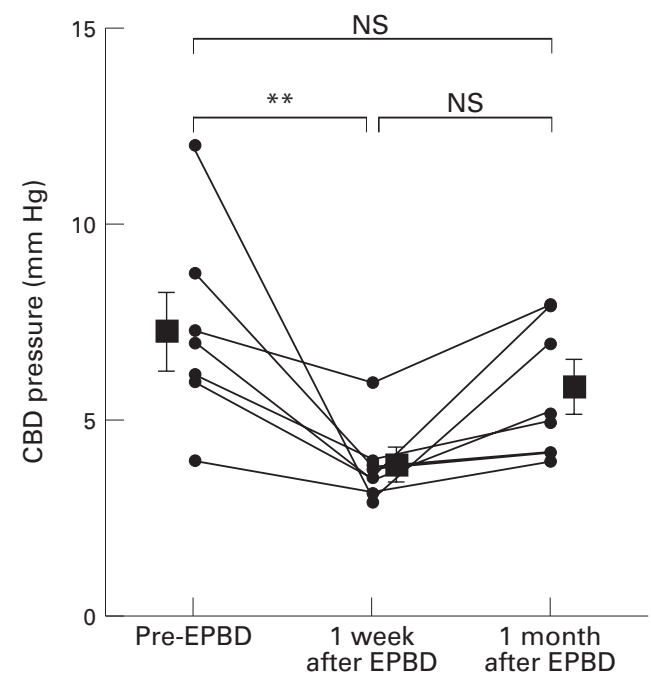

Figure 1: Comparison of $C B D$ pressure before, one week, and one month after EPBD. ${ }^{\star \star} p<0.01$.

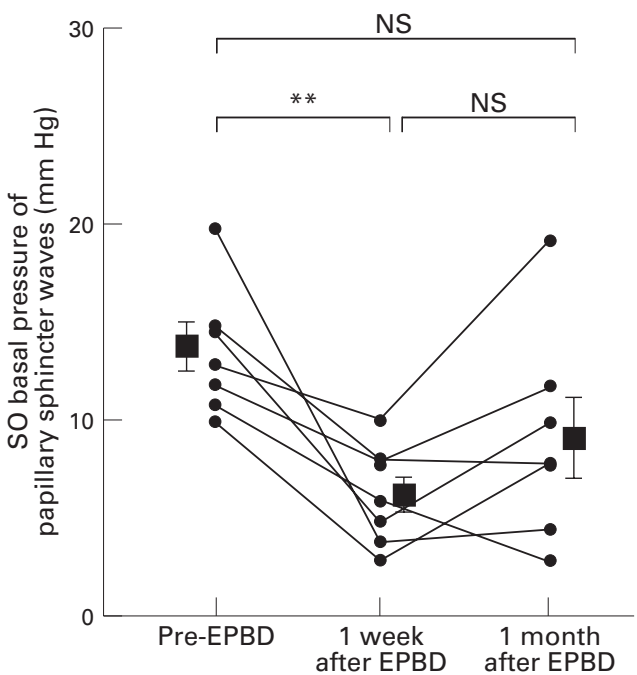

Figure 2: Comparison of SO basal pressure before, one week, and one month after EPBD. ${ }^{\star \star} p<0.01$.

basket impaction. There were however minor complications such as oozing of papilla $(100 \%)$ and abdominal discomfort or slight pain $(60 \%)$. There were also no pneumobilia after EPBD.

\section{Discussion}

It has been reported that EPBD is a safe and effective alternative to EST in the management of CBD stones; however, its effect on papillary function has yet to be elucidated and the importance of this has been recognised. ${ }^{12}$ This study was therefore undertaken to assess the effects of EPBD on the sphincter of Oddi.

In our study, SO function was significantly reduced one week after EPBD. One month after EPBD, SO peak pressure and frequency increased significantly, SO basal and CBD pressure tended to increase compared with values one week after EPBD, and there was no significant difference in all parameters between values before and one month after EPBD. These results suggest at least partial recovery of papillary function to the level before EPBD in 


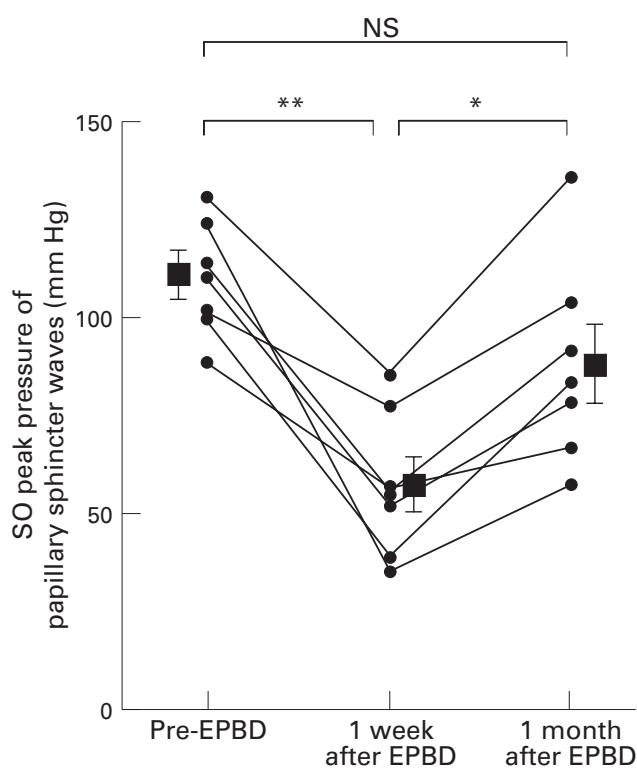

Figure 3: Comparison of SO peak pressure before, one week, and one month after EPBD. ${ }^{\star} p<0.05,{ }^{\star}{ }^{\star} p<0.01$.

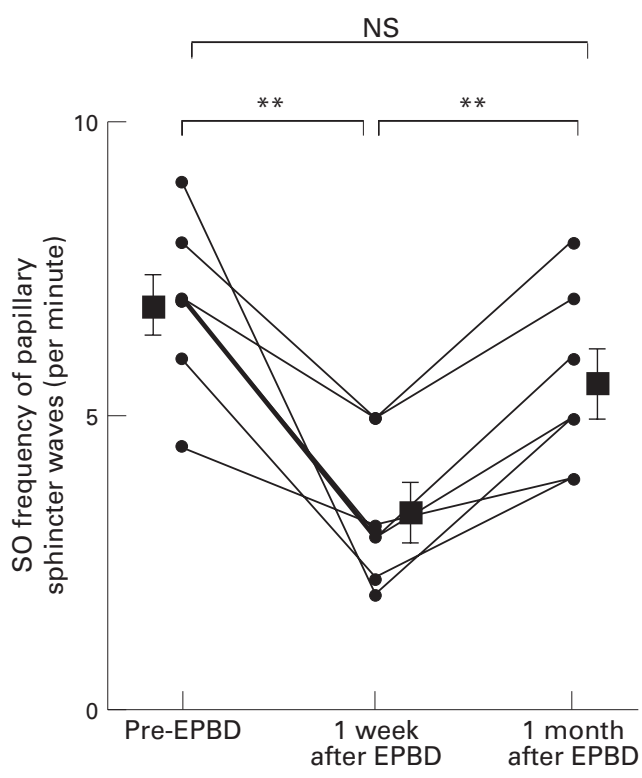

Figure 4: Comparison of SO frequency before, one week, and one month after EPBD. ${ }^{\star \star} p<0.01$.

one month. It has been reported that there is no significant difference between healthy controls and patients with bile duct stones with respect to basal pressure, and amplitude and frequency of the phasic wave of the SO. ${ }^{10}{ }^{11}$ Our data on SO function before EPBD are thought to be within the range of these reported levels. The decreased function of the SO one week after EPBD was close to the lowest level of the normal range reported in the other studies. ${ }^{12-14}$ Anatomical studies in pigs, in which EPBD was performed with an $8 \mathrm{~mm}$ balloon for 45-60 seconds, repeated twice, showed no rupture of SO smooth muscle. ${ }^{5}$ Although this was not confirmed in our study, the preservation of SO muscle would be consistent with this result. Minami et al reported that EPBD with an $8 \mathrm{~mm}$ balloon did not alter SO function one month after the procedure in patients with
CBD stones. ${ }^{15}$ Our manometry data showed similar findings with a $10 \mathrm{~mm}$ balloon. With a $15 \mathrm{~mm}$ balloon, Staritz et al reported improvement of the increased CBD pressure eight months after EPBD in a patient with benign papillary stenosis. ${ }^{14}$ Further studies will be necessary to determine the effect of EPBD on SO function with different size balloons.

Several studies have assessed papillary function after EST, using endoscopic manometry. ${ }^{12}{ }^{16}$ In these studies, SO basal pressure and SO amplitude decreased markedly soon after EST, but SO amplitude recovered to some extent two years after EST. Since EST incises the $\mathrm{SO}$, the papillary function seems disturbed for at least one year. In our study, papillary function seemed to recover much faster after EPBD. However, papillary function should be studied for a longer period in order to evaluate the changes after EPBD compared with those after EST.

In a recent prospective multicentre study using EST, complications were reported in $11.7 \%$ cases, including significant haemorrhage in $1.9 \%$, pancreatitis in $6.7 \%$, and duodenal perforation in $0.5 \%$, with a 30 day procedure related mortality rate of $0.5 \%$. Apart from these immediate complications, recurrent problems were reported in $4-13 \%$, including delayed stenosis of the papilla in $1.3-3.4 \%$, cholangitis in $1.3-6.8 \%$, and stone recurrence in $2.7-5.8 \%$ of patients followed for two months to 13 years. ${ }^{17-24}$

On the other hand, Mathuna et al treated 100 EPBD patients who were followed up for a median of 16 months. They reported uncomplicated pancreatitis in $5 \%$ and recurrent symptomatic CBD stones in $2 \%$, with no papillary haemorrhage or clinical evidence of papillary stenosis. Furthermore they argued that these stones were not recurrent; failures were attributed to either inadequate dilatation of the papilla during the early learning phase of the technique or suboptimal postclearance cholangiography.

In this study, EPBD was performed for one minute and repeated three times to avoid abdominal discomfort and mild pain during the procedure as much as possible, while maintaining sufficient SO dilatation for stone removal. This procedure caused no severe complications such as bleeding, perforation, or pancreatitis. There were however minor complications such as oozing of papilla (100\%) after EPBD and abdominal discomfort or slight pain $(60 \%)$ during EPBD. In another series of 20 patients who underwent EPBD with a $10 \mathrm{~mm}$ balloon, using the same procedure (data not shown), there was one case of mild pancreatitis ( $5 \%)$. CBD stones have not recurred in the subjects who refused cholecystectomy after EPBD, although we recommend cholecystectomy after EPBD if gallstones are found. As discussed above, EPBD seems to be a relatively safe technique. However, some investigators have reported a high incidence of pancreatitis following EPBD treatment of benign papillary stenosis and papillary dysfunction. $^{2526}$ Therefore we believe that manometry need not be performed in all 
patients before EPBD; it should be done however if papillary dysfunction is suspected. As EPBD is not an established technique, further study is necessary to investigate late EPBD complications in comparison with those occurring after EST.

In conclusion, EPBD seemed to depress papillary function at least for one week, with recovery one month after the procedure. Longer term follow up with SO manometry should be performed to investigate further the effect of EPBD on SO function.

1 Mathuna PM, White P,Clarke E, Lennon J, Growe J. Endoscopic sphincteroplasty: a novel and safe alterative to papillotomy in the management of bile duct stones. Gut 1994; 35: $127-9$.

2 Mathuna PM, White P, Clarke E, Merriman R, Lennon JR and Crowe J. Endoscopic balloon sphincteroplasty (papillary dilatation) for bile duct stones: efficacy, safety, and lary dilatation) for bile duct stones: efficacy, safety, and follow-up

3 May GR, Cotton PB, Edmunds SEJ, Chong W. Removal of stones from the bole duct at ERCP without sphincterotomy. Gastrointest Endosc 1993; 39: 749-54.

4 Stariz M, Ewe K, Buschenfelde KHM. Endoscopic papillary dilatation for the treatment of common bile duct stone and papillary stenosis. Endoscopy 1983; 15: 197-8.

5 Mathuna PM, Siegenberg D, Gibbons D, Gorin D, O'Brien $\mathrm{M}$, Chuttani R, et al. The acute and long-term effect of balloon sphincteroplasty on papillary structure in pigs. Gastrointest Endosc 1996; 44: 650-5.

6 Takaaki J, Akaki H, Furuya S, Morita M, Fukui Y, Sato T, et al. Effect of cisapride on the motor activity of the sphincter of Oddi in humans: evaluation by endoscopic biliary manometry. Advances in Therapy 1994; 11: 177-82.

7 Okazaki K, Yamamoto Y, Ito K. Endoscopic measurement of papillary sphincter zone and pancreatic main ductal of papillary sphincter zone and pancreatic main ductal pressure in patients with

8 Lai KH, Peng NJ, Cheng JS, Lo GH, Wang EM, W'ng NM, et al. Gallbladder function and recurrent stones of the biliary tract in patients after endoscopic sphincterotomy Scand F Gastroenterol 1996; 31: 612-5.

9 Cotton P, Lehman G, Vennes J, Geenen J, Russell R, Meyers W, et al. Endoscopic sphincterotomy complications and their management: an attempt at consensus. Gastrointest Endosc 1991; 37: 383-93.

10 Toouli J, Geenen JE, Hogan WJ, Dodds WJ, Arndorfer RC. Sphincter of Oddi motor activity: a comparison between patients with common bile duct stones and controls. Gastroenterology 1982; 82: 111-7

11 Masi ED, Corazziari E, Habib FI, Fontana B, Gatti V, Fegiz $\mathrm{GF}$, et al. Manometric study of the sphincter of Oddi in patients with and without common bile stones. Gut 1984; 25: $275-8$.

12 Gregg JA, Carr-Locke DL. Endoscopic pancreatic and biliary manometry in pancreatic, biliary, and papillary disease, and after endoscopic sphincterotomy and surgical sphincteroplasty. Gut 1984; 25: 1247-54.

13 Staritz M, Poralla T, Ewe K, Buschenfelde KHM. Effect of glyceryl trinitrate on sphincter of Oddi motility and baseline pressure. Gut 1985; 26: 194-7.

14 Staritz M, Poralla T, Dormeyer HHE, Buschenfelde KHM. Endoscopic removal of common bile duct stones through the intact papilla after medical sphincter dilatation. Gastroenterology 1985; 88: 1807-11.

15 Minami A, Nakatsu T, Uchida N, Hirabayashi S, Fukuma $\mathrm{H}$, Morshed SA, et al. Papillary dilatation vs sphincterotomy in endoscopic removal of bile duct stones: a randomized trial with manometric function. Dig Dis $S c i$ 1995; 40: 2550-4.

16 Geenen JE, Toouli J, Hogan WJ, Dodds WJ, Stewart ET, Mavrelis P, et al. Endoscopic sphincterotomy: follow-up evaluation of effects on the sphincter of Oddi. Gastroenterevaluation of effects on
ology $1984 ; 87: 754-8$.

17 Freeman ML, Nelson DB, Sherman S, Haber GB, Herman ME, Dorsher PJ, et al. Complications of endoscopic biliary sphincterotomy. N Engl f Med 1996; 335: 909-18.

18 Vaira D, D'anna L, Ainley C, Dowsett J, Williams S, Baillie $\mathrm{J}$, et al. Endoscopic sphincterotomy in 1000 consecutive patients. Lancet 1989; ii: 431-3.

19 Prat F, Nalak NA, Pelletier G, Buffet C, Fritsch J, Choury $\mathrm{AD}$, et al. Biliary symptoms and complications more than 8 years after endoscopic sphincterotomy for choledocholithiasis. Gastroenterology 1996; 110: 894-9.

20 Seifert E, Gail K, Weismuller J. Langzeitresultate nach endoskopischer sphinkterotomie: follow-up studie aus 25 zentren in der Bundesrepubik. Dtsch Med Wochenschr 1982; 107: $610-4$.

21 Ikeda S, Tanaka $\mathrm{M}$, Matsumoto S, Yoshimoto $\mathrm{H}$, Ito $\mathrm{H}$. Endoscopic sphincterotomy: long-term results in 408 patients with complete follow-up. Endoscopy 1988; 20: patients.

22 Escourrou J, Cordova JA, Lazorthes F, Frexinos J, Ribet A. Early and late complications after endoscopic sphincterotomy for biliary lithiasis with and without the gall bladder 'in situ'. Gut 1984; 25: 598-602.

23 Hawes RH, Cotton PB, Vallon AG. Follow-up 6 to 11 years after duodenoscopic sphincterotomy for stones in patients with prior cholecystectomy. Gastroenterology 1990; 98: with prio

24 Jacobsen O, Matzen P. Long-term follow up study of patients after endoscopic sphincterotomy for choledocholithiasis. Scand F Gastroenterol 1987; 22: 903-6.

25 Bader M, Geenen JE, Hogan WJ, Dodds WJ, Venu R, Johnson GK. Endoscopic balloon dilatation of sphincter of Oddi in patients with suspected biliary dyskinesia: result of a prospective randomized trial [abstract]. Gastrointest Endosc 1986; 32: 158.

26 Kozarek RA. Balloon dilatation of the sphincter of Oddi. Endoscopy 1988; 20: 207-10. 